\section{RMD Open}

Rheumatic \&

Musculoskeletal Diseases

\title{
Delayed-release prednisone improves fatigue and health-related quality of life: findings from the CAPRA-2 double-blind randomised study in rheumatoid arthritis
}

\author{
Rieke Alten, ${ }^{1}$ Amy Grahn, ${ }^{2}$ Robert J Holt, ${ }^{3}$ Patricia Rice, ${ }^{4}$ Frank Buttgereit ${ }^{5}$
}

To cite: Alten R, Grahn A, Holt RJ, et al. Delayed-release prednisone improves fatigue and health-related quality of life: findings from the CAPRA-2 double-blind randomised study in rheumatoid arthritis. $R M D$ Open 2015;1:e000134. doi:10.1136/rmdopen-2015000134

- Prepublication history for this paper is available online. To view these files please visit the journal online (http://dx.doi.org/10.1136/ rmdopen-2015-000134).

Received 30 May 2015 Revised 22 July 2015 Accepted 27 July 2015

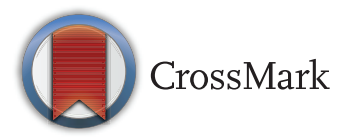

For numbered affiliations see end of article.

Correspondence to Dr Rieke Alten; rieke.alten@schlossparkklinik.de

\section{ABSTRACT}

Objectives: Like morning stiffness, fatigue is a common, debilitating symptom of rheumatoid arthritis (RA). Delayed-release (DR) prednisone is designed for evening administration (approximately 22:00) and releases $4 \mathrm{~h}$ later to coincide with the rise of nocturnal inflammatory cytokines associated with development of morning stiffness. The impact of DR prednisone on fatigue and other related patient-reported outcomes was analysed with data obtained from the Circadian Administration of Prednisone in Rheumatoid Arthritis (CAPRA) 2 study.

Methods: Patients with symptomatic RA $(n=350)$ despite treatment with a disease-modifying antirheumatic drug (DMARD) were randomised 2:1 to receive additional therapy with $\mathrm{DR}$ prednisone $5 \mathrm{mg}$ or placebo once daily for 12 weeks. Fatigue was assessed using validated instruments: the fatigue scale of the Functional Assessment of Chronic Illness TherapyFatigue (FACIT-F) and the vitality domain of the Short Form-36 (SF-36). General quality of life was assessed using the general score and individual domains of Functional Assessment of Cancer Therapy-General (FACT-G) and SF-36.

Results: The change from baseline to week 12 in FACIT-F score was statistically significantly different with DR prednisone/DMARD (3.8) versus placebo/ DMARD (1.6; difference 2.2, $p=0.0032$ ). Improvement in FACIT-F score correlated positively with clinical response. Compared with placebo/DMARD, DR prednisone/DMARD showed a significantly greater improvement in SF-36 vitality score (5.6, $p=0.001)$, physical component of SF-36 (2.3, $p=0.0003)$ and general score with FACT-G (2.6, $p=0.0233)$.

Conclusions: DR prednisone in addition to a DMARD significantly improves fatigue and other aspects of health-related quality of life in patients with symptomatic RA compared with DMARD treatment alone.

Trial registration number: ClinicalTrials.gov NCT00650078.

\section{Key messages}

What is already known about this subject?

- Fatigue may be a troublesome and debilitating problem in many patients with rheumatoid arthritis (RA).

- Delayed-release (DR) prednisone was developed for night-time administration, with the active agent released approximately $4 \mathrm{~h}$ later, at around the same time as peak levels of proinflammatory cytokines.

What does this study add?

- The addition of DR prednisone to DMARD in patients with active RA significantly reduces fatigue compared with DMARD alone.

- Fatigue, reoccurrence of joint stiffness and pain during the day are correlated, suggesting a common underlying pathophysiological mechanism.

How might this impact on clinical practice?

- Patients with RA experiencing morning stiffness and fatigue despite treatment with DMARD may benefit from addition of DR prednisone.

\section{INTRODUCTION}

Despite the reduction in disease activity brought about by advances in synthetic and biological disease-modifying antirheumatic drug (DMARD) therapy, patients with rheumatoid arthritis (RA) commonly suffer from morning stiffness and pain, and associated functional disability. ${ }^{1-4}$ Morning stiffness is associated with elevated nocturnal levels of inflammatory cytokines, especially interleukin 6 (IL-6). ${ }^{3}{ }^{5}$ Glucocorticoid therapy ameliorates severity of morning stiffness and suppresses IL-6 levels, with a more pronounced effect when administered 
during the night (approximately 02:00) compared with the traditional time for dosing (approximately 06:0008:00). ${ }^{6}{ }^{7}$ However, waking at night to take treatment is inconvenient for most patients.

Delayed-release (DR) prednisone was developed for administration in the evening (approximately 22:00), with glucocorticoid released after a delay of approximately $4 \mathrm{~h}$. Once released, the drug's pharmacokinetics are the same as conventional immediate-release prednisone. ${ }^{8}$ Thus, the prednisone in DR prednisone peaks around the same time as IL- $6 .{ }^{3}$ The efficacy of DR prednisone administered in the evening in comparison with the same dose of conventional immediate-release prednisone administered in the morning was demonstrated with respect to reduced duration of morning stiffness and IL-6 levels in a 12-week, randomised, double-dummy study (Circadian Administration of Prednisone in Rheumatoid Arthritis (CAPRA) 1). ${ }^{9}$ Compared with baseline, the effects of DR prednisone on morning stiffness and IL- 6 levels were maintained when treatment was continued long term in a follow-on study, ${ }^{10}$ with no impact on the hypothalamic-pituitary-adrenal axis over and above that seen with existing conventional prednisone therapy. ${ }^{11}$

Like morning stiffness, fatigue is a common symptom of $\mathrm{RA}^{12-14}$ and has a marked adverse impact on patient quality of life. ${ }^{12}{ }^{15-17}$ Fatigue is a complex multidimensional feature of RA and other inflammatory conditions that is poorly understood but may reflect the impact of heightened disease activity, low mood, sleep disturbance, pain and other factors. ${ }^{18-23}$ There may also be common elements in the underlying pathophysiology of fatigue and morning stiffness, with IL-6 levels potentially implicated in these systemic features of inflammation in $\mathrm{RA}^{24} 25$

Although there may be a pronounced response of RA to treatment with biological therapies, as assessed using response criteria such as those from the American College of Rheumatology (ACR) or the European League Against Rheumatism (EULAR) that include swollen joints, tender joints and other markers of disease activity, such treatments do not appear to have comparable benefit on extra-articular systemic symptoms such as fatigue and possibly stiffness. ${ }^{26-28}$ Given the high patient need for adequate treatment of these disabling aspects of RA, it was of interest to determine the effect of DR prednisone on fatigue and other patient-reported outcomes that assess health-related quality of life using data from the CAPRA-2 study.

\section{PATIENTS AND METHODS}

\section{Design}

Details of the CAPRA-2 study have been reported in full elsewhere. $^{29}$ Briefly, this 12-week, double-blind, parallel-group study randomised patients to treatment with DR prednisone $5 \mathrm{mg}$ or placebo once daily with or after the evening meal, in addition to existing stable
DMARD treatment. The primary efficacy end point was the proportion of patients with a $20 \%$ improvement in RA signs and symptoms according to ACR criteria (ie, ACR20 response) at week 12. Key secondary end points were the change in duration of morning stiffness and the outcomes reported here between baseline and week 12.

The study was conducted in accordance with the International Conference on Harmonisation Guideline for Good Clinical Practice and the Declaration of Helsinki. The protocol was approved by central or local ethics committees (see Acknowledgements section for details), and all patients provided written informed consent. The trial was registered at ClinicalTrials.gov, number NCT00650078.

\section{Study centres}

This multicentre study involved rheumatologists from secondary or tertiary care centres in the USA (23 centres, 75 patients), Poland (10 centres, 145 patients), Hungary ( 9 centres, 102 patients), the UK ( 3 centres, 12 patients), Germany (3 centres, 3 patients) and Canada (2 centres, 75 patients).

\section{Patients}

Patients included in the study were aged $18-80$ years with a documented history of RA and were symptomatic (morning stiffness $\geq 45$ min duration on $\geq 4$ days within 7 days of screening; $\geq 4$ swollen and tender joints) despite taking DMARDs for at least 6 months. Patients treated with oral glucocorticoids within 6 weeks of the screening visit were excluded. Changes in DMARD therapy during the study were not permitted.

\section{Randomisation and blinding}

Patients were assigned a unique four-digit number. The randomisation schedule linked sequential numbers to treatment codes allocated at random with a 2:1 (active treatment vs placebo) randomisation ratio. The randomisation numbers were blocked, with patients within each block allocated to each of the treatment groups. The block size was not revealed. Randomisation to study medication was balanced by investigational site. Treatments were labelled with a three-digit number, and patients at each site received the tablets with the lowest available number. Tablets containing active treatment or placebo were identical in appearance. Both patients and investigators were blinded to treatment.

\section{Data collection and outcomes}

At each study visit (weeks 2, 6 and 12), disease activity was assessed using the 28-joint Disease Activity Score (DAS28). Patients assessed pain using a visual analogue scale (VAS) ranging from 0 (no pain) to $100 \mathrm{~mm}$ (very intense pain). Likewise, a VAS was used by patients to rate global disease activity on a scale ranging from 0 (not active at all) to $100 \mathrm{~mm}$ (extremely active). Patients 
also completed the Functional Disability Index of the Health Assessment Questionnaire (HAQ-DI).

Throughout the study, patients completed a daily diary card twice daily. In the mornings, they recorded the presence of any joint stiffness and its severity, the time of resolution of joint stiffness, and pain levels on waking. In the evening, patients recorded any reoccurrence of joint stiffness and pain during the day, and the intensity of pain. Patients also recorded daily use of analgesic medication.

Fatigue was assessed at baseline and week 12 using the Functional Assessment of Chronic Illness TherapyFatigue (FACIT-F) questionnaire, ${ }^{30} 31$ which has been validated for use in RA. ${ }^{30}$ The FACIT measurement system is a collection of questionnaires to measure health-related quality of life in chronic illnesses. FACIT-F includes a 13-item domain specifically focused on fatigue. Each item is assessed on a five-point scale $(0=$ not at all to $4=$ =very much $)$ giving a fatigue score range of 0-52 (higher score indicating less fatigue). The minimal clinically important change in the fatigue score is $3-4 .^{30}$ Fatigue was also assessed using the vitality domain of the 36-item Short-Form Health Survey (SF-36) ${ }^{33} 34$ The score ranges from $0=$ maximum disability to $100=$ no disability (higher score indicating less fatigue). The minimal clinically important change in the vitality domain score is $11 .^{35}$

The FACIT measurement system includes a generic core questionnaire, originally developed for patients with cancer (Functional Assessment of Cancer Therapy-General, FACT-G) ${ }^{31}$ This is a 27 -item instrument, with four domains (physical well-being, social/ family well-being, emotional well-being and functional well-being) that has been validated in patients with cancer and other chronic illnesses. FACT-G was used in this analysis to assess general health status as it has been validated in RA. ${ }^{31}$ General health status was also assessed using the scores from seven domains of the SF-36 (physical functioning, role physical, bodily pain, general health, social functioning, role emotional, mental health), and summary scores for physical components and mental components (including vitality). ${ }^{34}$ In both instruments, higher scores indicate less impact on health status. Patient global assessments were also undertaken.

\section{Statistical analysis}

The intent-to-treat (ITT) population was analysed, with a modified ITT (excluding those without baseline data) used for comparisons from baseline. All results relating to severity of morning stiffness, duration of morning stiffness, intensity of pain on waking, and reoccurrence of joint stiffness and pain were based on the data obtained from the daily diaries completed by patients. Reoccurrence of joint stiffness during the day was calculated as the percentage of days with joint stiffness reoccurrence over the 7 days prior to, and including, the study visit day ( $\geq 3$ days of data required). The least squares means (LSMs) for the absolute change from baseline were obtained from an analysis of covariance model with baseline value, treatment and geographic region as factors. Model effects were from the type III estimates. Baseline observation carried forward imputation was used to compare treatment groups. Significance and $95 \%$ CI were established based on the mean relative percentage change from baseline. Point biserial correlation of daily reoccurrence of joint stiffness (yes or no) and pain (100 mm VAS) for all patients was performed. Statistical methods used did not control for multiple testing.

\section{RESULTS}

\section{Patient disposition}

As reported previously, a total of 350 patients were randomised to treatment (231 patients to DR prednisone and 119 patients to placebo); 323 patients (92.3\%) completed the study. ${ }^{29}$ Demographic and baseline disease characteristics were generally well balanced between the two treatment groups. After 12 weeks, $48 \%$ of patients treated with DR prednisone achieved an ACR20 response, compared with $29 \%$ of patients who received placebo $(19 \%$ treatment difference, $\mathrm{p}<0.001)$.

\section{Impact of treatment on measures of fatigue}

There was a statistically significant difference between treatments in the change from baseline to week 12 in FACIT-F score (LSM difference 2.2, $\mathrm{p}=0.0032$ ), favouring DR prednisone, as compared with placebo. The within-group change from baseline to week 12 in FACIT-F score was clinically meaningful with DR prednisone/DMARD (3.8) but not with placebo/DMARD (1.6; figure 1). Compared with placebo/DMARD, DR prednisone/DMARD showed significantly greater improvement in SF-36 vitality domain score (5.6, $\mathrm{p}=0.001$; table 1$)$.

\section{Correlation between improvement in fatigue and measures of disease responses}

A comparison of the mean change from baseline in FACIT-F score within treatment, by responder status for ACR20 was performed. This showed there was correlation between improvement in FACIT-F score and ACR20 response status, regardless of treatment arm (figure 2). Furthermore, those who received DR prednisone and who reached ACR20 response had statistically better FACIT-F scores as compared with those not reaching ACR20 response (5.5 V. 2.2, $\mathrm{p}<0.0001)$. There was also correlation between FACIT-F score and response status defined by DAS28 (not shown).

\section{Impact of treatment on other measures of quality of life}

Compared with placebo/DMARD, treatment with DR prednisone/DMARD showed a significantly greater improvement in FACT-G score $(2.6, \mathrm{p}=0.0233)$ and other aspects of well-being (table 2). Compared with placebo/ DMARD, treatment with DR prednisone/DMARD also 
Figure 1 Absolute change in FACIT-F score from baseline to week 12 (DMARD, diseasemodifying antirheumatic drug; FACIT-F, Functional Assessment of Chronic Illness TherapyFatigue; LSM, least squares mean).

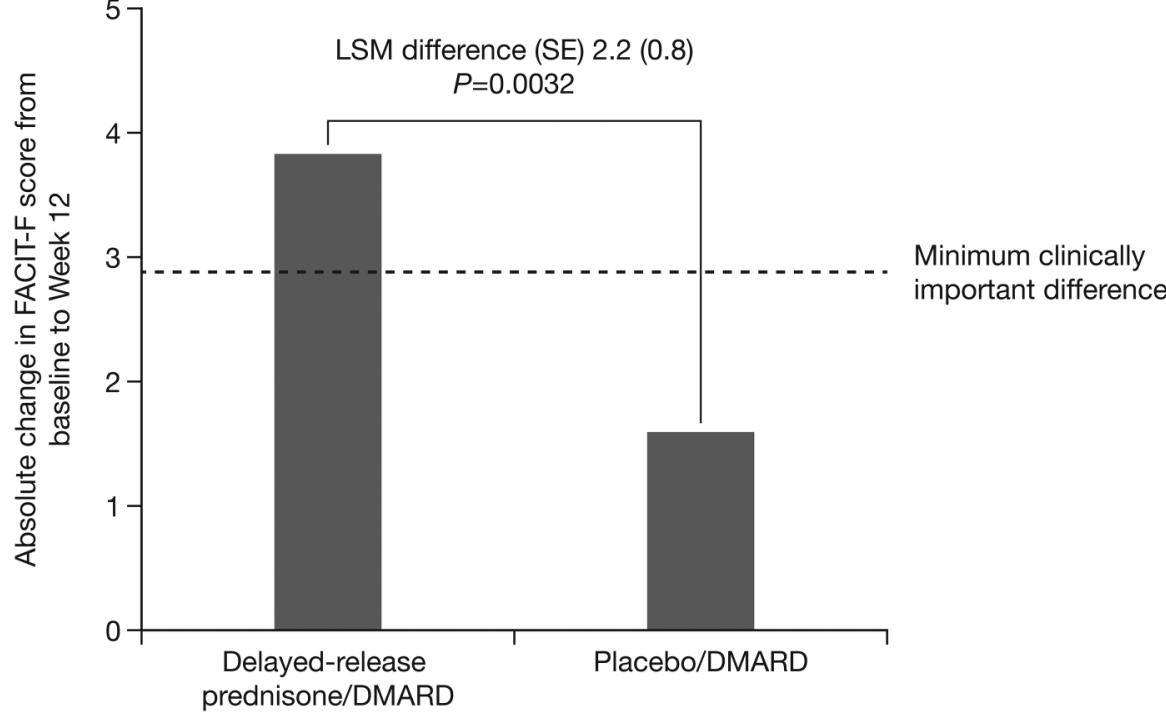

LSM, least squares mean; SE, standard error showed a significantly greater improvement in physical component summary score of SF-36 (2.3, $\mathrm{p}=0.0003)$ and in some individual domains (table 3 ).

Impact of treatment on other patient-reported outcomes Compared with placebo/DMARD, treatment with DR prednisone/DMARD significantly reduced reoccurrence of joint stiffness during the day $(-27.0 \%$ of days vs $-7.1 \%, \mathrm{p}=0.03$; table 4). Pain during the day also decreased for all patients, with no significant difference between treatment groups, although there was a significant reduction in daily analgesic use with active treatment $(-18.7 \%$ vs $1.9 \%$ days, $\mathrm{p}=0.02)$ and patient global assessment (treatment difference -25.3, $\mathrm{p}=0.01$ ). Regardless of treatment, there was moderate correlation between reoccurrence of joint stiffness and pain during the day $(\mathrm{r}=0.47)$.

\section{DISCUSSION}

The analysis of the CAPRA-2 study reported here demonstrates that low-dose DR prednisone added to DMARD therapy has a beneficial impact on patientreported outcomes (reoccurrence of joint stiffness, SF-36 physical functioning, fatigue and other aspects of health-related quality of life) in patients who are symptomatic despite DMARD treatment. Current DMARD and biological treatments have shown varied impact on fatigue. ${ }^{26} 28{ }^{36}$ Consequently, there is considerable need for treatments that have a positive and clinically relevant impact on the fatigue.

Fatigue was assessed using instruments previously validated or used in RA. ${ }^{31} 32{ }^{35}$ Fatigue is a complex feature of inflammatory conditions such as RA, and includes mental and physical aspects. ${ }^{15} 18-2123$ There appears to be interaction with sleep, pain and mood. ${ }^{20}{ }^{22}$ Interestingly, IL-6 has been implicated in sleep disturbance and low mood, as well as in fatigue associated with

Table 1 Impact of treatment on measures of fatigue

\begin{tabular}{|c|c|c|c|c|c|c|c|}
\hline \multirow[b]{2}{*}{ Measure of fatigue } & \multicolumn{3}{|c|}{ DR prednisone/DMARD } & \multicolumn{3}{|c|}{ Placebo/DMARD } & \multirow{2}{*}{$\begin{array}{l}\text { Treatment } \\
\text { difference } \\
\text { (95\% Cl) } ¥\end{array}$} \\
\hline & Baseline & Week 12 & Difference & Baseline & Week 12 & Differenceł & \\
\hline $\begin{array}{l}\text { Mean FACIT-F score } \\
\text { (SD) }\end{array}$ & $\begin{array}{l}28.8 \\
(10.4)\end{array}$ & $\begin{array}{l}32.5 \\
(10.9)\end{array}$ & 3.8 & $\begin{array}{l}28.7 \\
(10.7)\end{array}$ & 30.3 & 1.6 & $2.2(0.8 \text { to } 3.7)^{*}$ \\
\hline Range & $0-50$ & $0-52$ & & $3-49$ & $0-52$ & & \\
\hline $\begin{array}{l}\text { Mean SF-36 vitality domain } \\
\text { (SD)§ }\end{array}$ & $\begin{array}{l}44.5 \\
(19.4)\end{array}$ & $\begin{array}{l}51.6 \\
(20.6)\end{array}$ & $\begin{array}{l}7.0 \\
(16.5)\end{array}$ & $\begin{array}{l}43.1 \\
(19.3)\end{array}$ & $\begin{array}{l}44.9 \\
(19.8)\end{array}$ & $\begin{array}{l}1.8 \\
(14.1)\end{array}$ & $5.6(2.3 \text { to } 8.9)^{\star \star}$ \\
\hline Range & $0-100$ & $0-100$ & & $0-94$ & $0-100$ & & \\
\hline
\end{tabular}

${ }^{*} \mathrm{p}=0.0032$

${ }^{* *} p=0.0010$.

ILSM difference for FACIT-F score.

§Absolute difference from baseline, using baseline observation carried forward imputation.

DMARD, disease-modifying antirheumatic drug; DR, delayed-release; FACIT-F, Functional Assessment of Chronic IIIness Therapy-Fatigue;

LSM, least squares mean; SF-36, Short Form-36. 
Figure 2 Improvement in FACIT-F fatigue score according to ACR20 response status (ACR, American College of Rheumatology; DMARD, disease-modifying antirheumatic drug; FACIT-F, Functional Assessment of Chronic Illness Therapy-Fatigue).

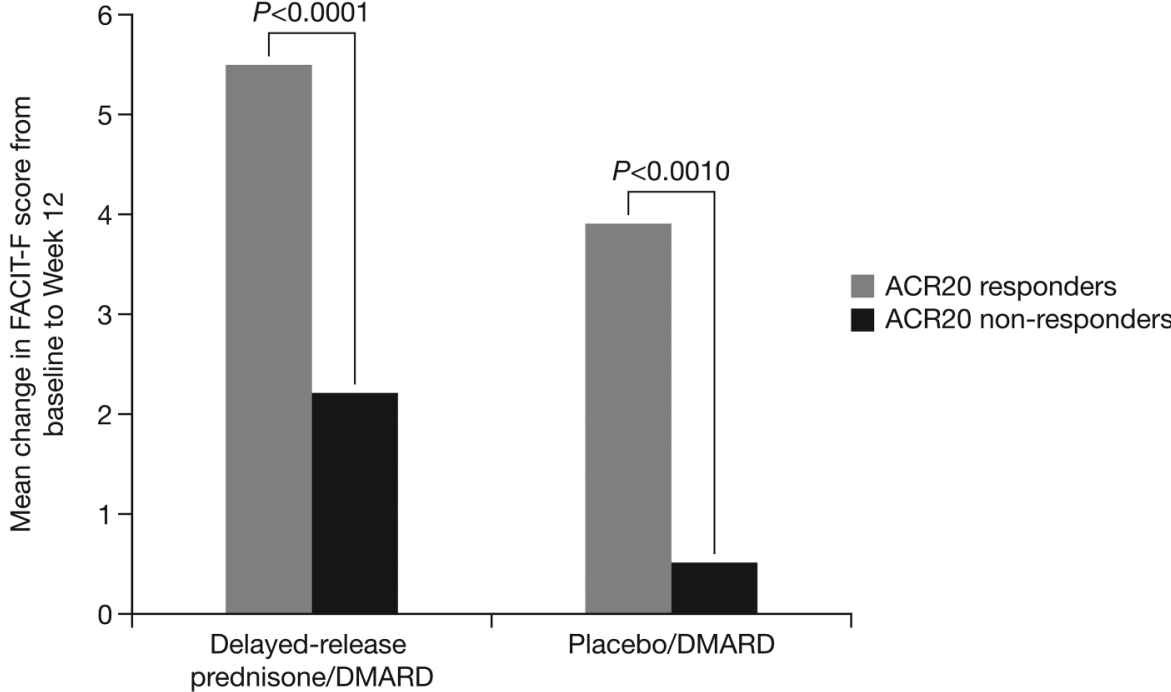

RA and fibromyalgia. ${ }^{24} 37$ There is also evidence to support a link between systemic inflammation (as indicated by elevated levels of IL- 6 and other markers) and fatigue in conditions as diverse as cancer and type 2 diabetes, ${ }^{38-40}$ and indication of an impact of IL- 6 on fatigue and mood in healthy volunteers. ${ }^{41}$ In fibromyalgia, there is evidence of an association between elevated IL-6 levels and a glucocorticoid receptor dysfunction. ${ }^{42}$ Although there are still unanswered questions about the pathophysiology of fatigue, the beneficial impact of the glucocorticoid chronotherapy on fatigue reported here is consistent with a causative role of IL-6 in fatigue, like that previously reported for morning stiffness. ${ }^{5}{ }^{25}$

Core data sets in RA do not adequately capture response of fatigue to treatment. ${ }^{36}$ Patient-reported outcomes provide important information on disease control, as indicated by the finding that $36 \%$ of patients with RA report a different level of global disease control than their physicians. ${ }^{43}$ Indeed, a 'biopsychosocial model' of disease is appropriate for RA, with patientreported data collected using validated and reliable questionnaires contributing important information to support shared decision-making. ${ }^{44}$ Consistent with this model, regulatory bodies such as the European Medicines Agency and the Institute for Quality and Efficiency in Health Care (IQWiG) in Germany take into account patient-reported outcomes and clinical disease measures when reaching decisions on approval and reimbursement of medications. Recognising the importance of the patient perspective, the WHO introduced the International Classification for Functioning, Disability and Health (ICF), which aims to shift the focus from causes of disability to the impact on the patient. Of note is the importance of patient participation in measuring health states such as RA flare, which includes fatigue and other domains. ${ }^{45}$

With regard to RA, this suggested shift in thinking is broadening the aim of treatment to encompass not only clinical remission, demonstrated by measures such as swollen joint count but also functional remission, demonstrated by an improvement in patient quality of life (or at the least, maintenance or reduction in rate of decline in quality of life). The participation of patients in different Outcome Measures in Rheumatology (OMERACT) activities has resulted in recognition of the importance of health domains such as fatigue, well-being and sleep pattern not previously included in standard assessments of RA. ${ }^{46}$ The composite index, Rheumatoid Arthritis Impact of Disease (RAID), has been developed to include the domains of pain, function, fatigue, physical and psychological well-being, sleep disturbance and coping. ${ }^{47}$ The use of measures such as RAID may affect data collected in future trials. ${ }^{48}$

A weakness of this study was its short duration of 12 weeks. It remains to be seen if the beneficial impact of DR prednisone on fatigue is maintained over the longer term. However, in an earlier study with DR prednisone, reductions from baseline in duration of morning stiffness and levels of IL-6 were maintained for up to 12 months. ${ }^{10}$ If IL-6 is involved in the pathophysiology of fatigue, as suggested by some studies, ${ }^{24}$ it might be anticipated that the beneficial effects on fatigue will also be sustained, though this has yet to be demonstrated. Although the study assessed pain, fatigue and overall health-related quality of life, CAPRA-2 did not include validated instruments to assess any impact of treatment on sleep duration and quality. Given the links between sleep and fatigue, this is a limitation of CAPRA-2. Statistical tests did not control for multiple testing, with the consequent risk of showing significance occasionally, even when the difference between the underlying populations is not significant. CAPRA-2 investigated the benefits of adding DR prednisone to prednisone-naïve patients receiving conventional DMARDs. It remains to be seen if similar benefits of adding DR prednisone are observed in patients receiving biological DMARD treatment or in patients previously on traditional prednisone and DMARDs. However, the 9-month open-label 
Table 2 Impact of treatment on FACT-G score and domains

\begin{tabular}{|c|c|c|c|c|c|c|c|}
\hline \multirow[b]{2}{*}{ Mean total/domain score (SD) } & \multicolumn{3}{|c|}{ DR prednisone/DMARD } & \multicolumn{3}{|c|}{ Placebo/DMARD } & \multirow{2}{*}{$\begin{array}{l}\text { Treatment } \\
\text { difference }(95 \% \mathrm{Cl})\end{array}$} \\
\hline & Baseline & Week 12 & Difference & Baseline & Week 12 & Difference & \\
\hline FACT-G ( score) & $67.3(16.6)$ & $71.1(18.0)$ & $3.6(10.4)$ & $68.1(14.5)$ & $69.1(15.3)$ & $1.0(9.8)$ & $2.6(0.4 \text { to } 4.8)^{*}$ \\
\hline Range & $14-105$ & $27-107$ & & $29-96$ & $32-104$ & & \\
\hline Physical well-being & $16.7(5.3)$ & $18.8(5.7)$ & $2.0(4.1)$ & $16.8(5.6)$ & $17.9(5.0)$ & $1.1(3.9)$ & $0.9(0.1 \text { to } 1.8)^{*}$ \\
\hline Social/family well-being & $20.1(5.6)$ & $19.9(6.3)$ & $-0.26(5.0)$ & $20.6(4.9)$ & $20.0(5.1)$ & $-0.6(4.2)$ & $0.2(-0.8,1.2)$ \\
\hline Emotional well-being & $14.5(5.1)$ & $15.5(5.3)$ & $1.0(3.4)$ & $14.6(4.7)$ & $15.5(4.9)$ & $0.9(2.9)$ & $0.1(-0.6$ to 0.8$)$ \\
\hline Functional well-being & $16.0(5.8)$ & $17.0(5.6)$ & $1.0(4.1)$ & $16.2(5.3)$ & $16.0(5.4)$ & $-0.21(4.2)$ & $1.2(0.3 \text { to } 2.0)^{\star \star}$ \\
\hline
\end{tabular}

${ }^{*} \mathrm{p} \leq 0.0297$

${ }^{* *} \mathrm{p}=0.0065$.

DMARD, disease-modifying antirheumatic drug; DR, delayed-release; FACT-G, Functional Assessment of Cancer Therapy-General.

Table 3 Impact of treatment on SF-36 component scores and domains

\begin{tabular}{|c|c|c|c|c|c|c|c|}
\hline \multirow{2}{*}{$\begin{array}{l}\text { Mean component/domain } \\
\text { score (SD) }\end{array}$} & \multicolumn{3}{|c|}{ DR prednisone/DMARD } & \multicolumn{3}{|c|}{ Placebo/DMARD } & \multirow{2}{*}{$\begin{array}{l}\text { Treatment } \\
\text { difference }(95 \% \mathrm{Cl})\end{array}$} \\
\hline & Baseline & Week 12 & Difference & Baseline & Week 12 & Difference & \\
\hline Physical component & $31.6(7.0) \S$ & $35.1(8.1)$ & $3.4(5.8)$ & $31.5(6.9)$ & $32.7(7.3)$ & $1.2(5.1)$ & $2.3(1.1 \text { to } 3.5)^{\star}$ \\
\hline Range & $14-56$ & $14-56$ & & $18-48$ & $15-58$ & & \\
\hline Mental component & $45.3(10.7) \S$ & 46.9 (10.7) 21-70 & $1.6(7.3)$ & $45.4(9.6)$ & $45.9(9.6)$ & $0.5(6.3)$ & $1.1(-0.4$ to 2.5$)$ \\
\hline Range & $17-68$ & & & $23-64$ & $14-64$ & & \\
\hline Physical functioning & $40.2(21.2)$ & $47.3(24.1)$ & $7.1(16.5)$ & $40.7(20.5)$ & $44.2(22.3)$ & $3.5(13.8)$ & $3.6(0.2 \text { to } 7.0)^{* *}$ \\
\hline Range & 0-95 & $0-100$ & & $0-90$ & $0-100$ & & \\
\hline Role physical & $44.5(22.3)$ & $50.8(23.8)$ & $6.0(20.1)$ & $43.3(21.9)$ & $45.4(21.1)$ & $2.1(14.6)$ & $4.5(0.7 \text { to } 8.3)^{* *}$ \\
\hline Range & $0-100$ & $0-100$ & & $0-100$ & $0-100$ & & \\
\hline Bodily pain & $34.4(16.2)$ & $45.7(20.5)$ & $11.3(17.8)$ & $34.0(15.5)$ & $38.4(18.8)$ & $4.5(16.1)$ & $7.0(3.3 \text { to } 10.7)^{\star}$ \\
\hline Range & $0-84$ & $0-100$ & & $0-74$ & $0-100$ & & \\
\hline General health & $39.8(18.4)$ & $44.6(20.1)$ & 4.7 (12.9) & $40.6(16.5)$ & $41.9(17.1)$ & $1.3(13.7)$ & $3.3(0.5 \text { to } 6.2)^{\star \star}$ \\
\hline Range & $0-97$ & $0-97$ & & $0-92$ & $5-100$ & & \\
\hline Social functioning & $57.9(25.6)$ & $63.9(25.1)$ & 5.9 (18.9) & $56.5(23.3)$ & $58.5(23.7)$ & $2.0(19.8)$ & $4.4(0.5 \text { to } 8.4)^{\star \star}$ \\
\hline Range & $0-100$ & $0-100$ & & $0-100$ & $0-100$ & & \\
\hline Role emotional & $57.2(28.8)$ & $59.6(26.6)$ & $2.5(22.5)$ & $56.0(25.6)$ & $58.5(27.1)$ & $2.5(21.2)$ & $0.7(-3.6$ to 5.1$)$ \\
\hline Range & $0-100$ & $0-100$ & & $0-100$ & $0-100$ & & \\
\hline Mental health & $59.1(20.7)$ & $63.7(21.1)$ & $4.6(15.7)$ & $61.0(20.0)$ & 62.5 (19.5) & $1.5(12.3)$ & $2.7(-0.4$ to 5.7$)$ \\
\hline Range & $0-100$ & $10-100$ & & $10-95$ & $0-100$ & & \\
\hline
\end{tabular}

${ }^{*} \mathrm{p} \leq 0.0003$

tab 0.0374 .

SData missing for two patients.

DMARD, disease-modifying antirheumatic drug; DR, delayed-release; SF-36, Short Form-36. 
Table 4 Impact of treatment on other patient-reported outcomes

\begin{tabular}{|c|c|c|c|c|}
\hline $\begin{array}{l}\text { Relative per cent change from baseline } \\
\text { in median patient-reported outcome }\end{array}$ & $\begin{array}{l}\text { DR prednisone/ } \\
\text { DMARD }\end{array}$ & Placebo/DMARD & $\begin{array}{l}\text { Treatment } \\
\text { difference }(95 \% \mathrm{Cl})\end{array}$ & p Value \\
\hline Days with recurrence of joint stiffness & -27.0 & -7.1 & $-19.9(-37.7$ to -2.1$)$ & 0.03 \\
\hline Pain during the day (100 mm VAS) & -25.5 & -31.7 & $-6.14(-37.8$ to 50.1$)$ & 0.78 \\
\hline Patient global assessment & -17.8 & 7.49 & $-25.3(-44.6$ to -5.9$)$ & 0.01 \\
\hline Days with analgesic use & -18.7 & 1.9 & $-20.6(-37.3$ to -4.0$)$ & 0.02 \\
\hline
\end{tabular}

follow-on trial of the controlled CAPRA-1 study demonstrated significant morning stiffness improvements in patients on stable DMARDs and conventional prednisone who were switched to equivalent doses of DR prednisone. $^{10}$

\section{CONCLUSION}

In conclusion, there is a theoretical rationale for a beneficial impact of DR prednisone on fatigue, based on the targeted suppression of the inflammatory cytokine IL-6 when it is most elevated during the night. This analysis of results from the CAPRA-2 study is consistent with the concept that higher levels of inflammation may mediate fatigue and that directed therapies may be required to address it. ${ }^{49}$ In patients with symptomatic RA despite the use of DMARDs, the addition of DR prednisone $5 \mathrm{mg}$ / day for 12 weeks resulted in a statistically significant and clinically meaningful improvement in measures of fatigue and improved other aspects of health-related quality of life.

\author{
Author affiliations \\ ${ }^{1}$ Schlosspark-Klinik, University Medicine Berlin, Berlin, Germany \\ ${ }^{2}$ Horizon Pharma, Deerfield, Illinois, USA \\ ${ }^{3}$ University of Illinois-Chicago, Chicago, Illinois, USA \\ ${ }^{4}$ Premier Research, Naperville, Illinois, USA \\ ${ }^{5}$ Charité University Hospital, Berlin, Germany
}

Acknowledgements The authors thank all the patients who took part in the CAPRA-2 study. The involvement of the following investigators (and ethical bodies approving the study) in each participating country is gratefully acknowledged: Canada (approved by IRB Services)—M Lee, Ajax, ON; J Rodrigues, Windsor, ON; Germany (approved by Landesamt für Gesundheit und Soziales, Geschäftsstelle der Ethik-Kommission des Landes Berlin for study authors RA and FB) -K Krueger, Munich (Ethik-Kommission der Medizinischen Fakultät der Ludwig-Maximilians-Universität München); Hungary (approved by the Central Ethics Committee)—T Balazs, Békéscsaba; J Gál, Kecskemét; L Náfrádi, Szombathely; K Nékám, Budapest; L Sámson, Szolnok; P Surányi, Debrecen; S Szántó, Debrecen; I Szombati, Budapest; K Takács, Kiskunhalas; Poland (approved by the Central Ethics Committee)-J Brzezicki, Elblag; A Dudek, Warszawa; S Jeka, Torun; S Mackiewicz, Poznań; M Majdan, Lublin; Z Ruzga, Wrocław; S Sierakowski, Bialystok; M Sochocka-Bykowska, Sopot; J Supronik, Białystok; J Szechinski, Wroclaw; UK -M George, Wirral (Cheshire Research Ethics Committee); J Kirwan, Bristol (North Somerset and South Bristol Research Ethics Committee); B Szenbenyi, Grimsby (South Humber Research Ethics Committee); USA (unless stated otherwise, approved by Schulman Associates Institutional Review Board)-M Archuleta, Wheat Ridge, CO; B Bode, Tucson, AZ (University of Arizona Human Subjects Protection Program); C Codding, Oklahoma City, OK; L Cruse, Tampa, FL; R DeGarmo, Greer, SC; A Dikranian, San Diego, CA; M Fairfax, Mesa, AZ; D Furst, Los Angeles, CA (Western Institutional Review
Board); E Goldberger, Tuledo, OH; M Hagan, Billings, MT; J Huff, San Antonio, TX; B Huh, Los Angeles, CA; W Kades, Los Angeles, CA; K Kempf, San Antonio, TX; A Kennedy, Vero Beach, FL; A Khan, Bellevue, WA; S Kimmel, Tamarac, FL; D Kirby, Belmont, NC; E Lee, Upland, CA; M Lowenstein, Palm Harbor, FL; DP Mehta, Elizabethtown, KY; R Rapoport, Fall River, MA; D Raskin, Pacific Palisades, CA; R Trapp, Springfield, IL; all in the USA. The authors thank Dr Diane Storey of Direct Publishing Solutions Ltd for medical writing and editorial assistance, which was funded by Horizon Pharma.

Contributors RA and FB were involved in conception and design, data collection and analysis, critical revision and final approval of the manuscript. $A G$ and RJH were involved in conception and design, data analysis, manuscript writing and final approval of the manuscript. PR was involved in statistical analysis, critical revision and final approval of the manuscript. All authors take full responsibility for the content of the paper.

Funding Horizon Pharma (formerly Nitec Pharma), Mannheim, Germany and Northbrook, Illinois, USA.

Competing interests RA received consultancy fees, honoraria and travel expenses from Merck Serono and Horizon Pharma (formerly Nitec Pharma). $A G$ is an employee of Horizon Pharma and has stock options. RJH received consultancy fees and/or travel expenses from Horizon Pharma, Hospira and Pozen. PR is an employee of Premier Research. FB received consultancy fees, honoraria and travel expenses from Horizon Pharma (formerly Nitec Pharma) and Mundipharma International Ltd, and grant support from Horizon Pharma.

Ethics approval Central or local ethics committees appropriate for each study centre, detailed in Acknowledgements.

Provenance and peer review Not commissioned; externally peer reviewed.

Data sharing statement No additional data are available.

Open Access This is an Open Access article distributed in accordance with the Creative Commons Attribution Non Commercial (CC BY-NC 4.0) license, which permits others to distribute, remix, adapt, build upon this work noncommercially, and license their derivative works on different terms, provided the original work is properly cited and the use is non-commercial. See: http:// creativecommons.org/licenses/by-nc/4.0/

\section{REFERENCES}

1. Khan NA, Yazici Y, Calvo-Alen J, et al. Reevaluation of the role of duration of morning stiffness in the association of rheumatoid arthritis activity. J Rheumatol 2009;36:2435-42.

2. Phillips S, Dow L. Impact of impaired morning function on quality of life in rheumatoid arthritis: results of an exploratory patient survey. Int J Clin Rheumatol 2012;7:597-606.

3. Straub RH, Cutolo M. Circadian rhythms in rheumatoid arthritis: implications for pathophysiology and therapeutic management. Arthritis Rheum 2007;56:399-408.

4. Yazici Y, Erkan D, Peterson MG, et al. Morning stiffness: how common is it and does it correlate with physician and patient global assessment of disease activity? J Rheumatol 2001;28:1468-9.

5. Kirwan JR, Clarke L, Hunt LP, et al. Effect of novel therapeutic glucocorticoids on circadian rhythms of hormones and cytokines in rheumatoid arthritis. Ann NY Acad Sci 2010;1193:127-33.

6. Arvidson NG, Gudbjörnsson B, Larsson A, et al. The timing of glucocorticoid administration in rheumatoid arthritis. Ann Rheum Dis 1997;56:27-31. 
7. Buttgereit F, Burmester GR, Straub RH, et al. Exogenous and endogenous glucocorticoids in rheumatic diseases. Arthritis Rheum 2011;63:1-9.

8. Derendorf $\mathrm{H}$, Ruebsamen $\mathrm{K}$, Clarke $\mathrm{L}$, et al. Pharmacokinetics of modified-release prednisone tablets in healthy subjects and patients with rheumatoid arthritis. J Clin Pharmacol 2013;53:326-33.

9. Buttgereit F, Doering G, Schaeffler A, et al. Efficacy of modified-release versus standard prednisone to reduce duration of morning stiffness of the joints in rheumatoid arthritis (CAPRA-1): a double-blind, randomised controlled trial. Lancet 2008;371:205-14.

10. Buttgereit F, Doering G, Schaeffler A, et al. Targeting pathophysiological rhythms: prednisone chronotherapy shows sustained efficacy in rheumatoid arthritis. Ann Rheum Dis 2010;69:1275-80.

11. Alten R, Doering G, Cutolo M, et al. Hypothalamus-pituitary-adrenal axis function in patients with rheumatoid arthritis treated with night-time-release prednisone. J Rheumatol 2010;37:2025-31.

12. Hewlett S, Cockshott Z, Byron M, et al. Patients' perceptions of fatigue in rheumatoid arthritis: overwhelming, uncontrollable, ignored. Arthritis Rheum 2005;53:697-702.

13. Hewlett S, Choy E, Kirwan J. Furthering our understanding of fatigue in rheumatoid arthritis. $J$ Rheumatol 2012;39:1775-7.

14. Wolfe F, Hawley DJ, Wilson K. The prevalence and meaning of fatigue in rheumatic disease. J Rheumatol 1996;23:1407-17.

15. Campbell RC, Batley M, Hammond A, et al. The impact of disease activity, pain, disability and treatments on fatigue in established rheumatoid arthritis. Clin Rheumatol 2012;31:717-22.

16. Feldthusen $\mathrm{C}, \mathrm{Bj}$ örk $\mathrm{M}$, Forsblad-d'Elia $\mathrm{H}$, et al. Perception, consequences, communication, and strategies for handling fatigue in persons with rheumatoid arthritis of working age-a focus group study. Clin Rheumatol 2013;32:557-66.

17. Franklin AL, Harrell TH. Impact of fatigue on psychological outcomes in adults living with rheumatoid arthritis. Nurs Res 2013;62:203-9.

18. Nicassio PM, Ormseth SR, Custodio MK, et al. A multidimensional model of fatigue in patients with rheumatoid arthritis. J Rheumatol 2012;39:1807-13.

19. Nikolaus S, Bode C, Taal E, et al. Fatigue and factors related to fatigue in rheumatoid arthritis: a systematic review. Arthritis Care Res 2013;65:1128-46.

20. Roehrs T, Diederichs C, Gillis M, et al. Nocturnal sleep, daytime sleepiness and fatigue in fibromyalgia patients compared to rheumatoid arthritis patients and healthy controls: a preliminary study. Sleep Med 2013;14:109-15.

21. Staud R. Peripheral and central mechanisms of fatigue in inflammatory and noninflammatory rheumatic diseases. Curr Rheumatol Rep 2012;14:539-48.

22. Ulus $\mathrm{Y}$, Akyol $\mathrm{Y}$, Tander B, et al. Sleep quality in fibromyalgia and rheumatoid arthritis: associations with pain, fatigue, depression, and disease activity. Clin Exp Rheumatol 2011;29(6 Suppl 69):S92-6.

23. van Dartel SA, Repping-Wuts JW, van Hoogmoed D, et al. Association between fatigue and pain in rheumatoid arthritis: does pain precede fatigue or does fatigue precede pain? Arthritis Care Res 2013;65:862-9.

24. Rohleder N, Aringer M, Boentert M. Role of interleukin-6 in stress, sleep, and fatigue. Ann NY Acad Sci 2012;1261:88-96.

25. Westhoff $G$, Buttgereit $F$, Zink A. Fatigue and morning stiffness are correlated in early arthritis and both are substantially improved by glucocorticoids. Ann Rheum Dis 2011;70(Suppl 3):289.

26. Chauffier K, Salliot C, Berenbaum F, et al. Effect of biotherapies on fatigue in rheumatoid arthritis: a systematic review of the literature and meta-analysis. Rheumatology 2011:51:60-8.

27. Cutolo M, Kitas GD, van Riel PL. Burden of disease in treated rheumatoid arthritis patients: going beyond the joint. Semin Arthritis Rheum 2014:43:479-88.

28. van Hoogmoed D, Fransen J, Repping-Wuts $\mathrm{H}$, et al. The effect of anti-TNF- $\alpha$ vs. DMARDs on fatigue in rheumatoid arthritis patients. Scand J Rheumatol 2012;42:15-19.
29. Buttgereit F, Mehta D, Kirwan J, et al. Low-dose prednisone chronotherapy for rheumatoid arthritis: a randomised clinical trial (CAPRA-2). Ann Rheum Dis 2013;72:204-10.

30. Cella D, Yount S, Sorensen M, et al. Validation of the Functional Assessment of Chronic Illness Therapy Fatigue Scale relative to other instrumentation in patients with rheumatoid arthritis. $J$ Rheumatol 2005;32:811-19.

31. Webster K, Cella D, Yost K. The Functional Assessment of Chronic Illness Therapy (FACIT) Measurement System: properties, applications, and interpretation. Health Qual Life Outcomes 2003;1:79.

32. Singh $\mathrm{H}$, Arya $\mathrm{S}$, Talapatra $\mathrm{P}$, et al. Assessment of fatigue in rheumatoid arthritis (by functional assessment of chronic illness therapy-fatigue score) and its relation to disease activity and anemia. $J$ Clin Rheumatol 2014;20:87-90.

33. Neuberger GB. Measures of fatigue. Arthritis Rheum 2003;49(5S): S175-83.

34. Ware JE, Sherbourne CD. The MOS 36-item short-form health survey (SF-36). I. Conceptual framework and item selection. Med Care 1992;30:473-83.

35. Pouchet J, Kherani RB, Brant R, et al. Determination of the minimal clinically important difference for seven fatigue measures in rheumatoid arthritis. J Clin Epidemiol 2008;61:705-13.

36. Minnock P, McKee G, Bresnihan B, et al. How much is fatigue explained by standard clinical characteristics of disease activity in patients with inflammatory arthritis? A longitudinal study. Arthritis Care Res 2014:66:1597-603.

37. Fragiadaki K, Tektonidou MG, Konsta M, et al. Sleep disturbances and interleukin 6 receptor inhibition in rheumatoid arthritis. J Rheumatol 2012;39:60-2.

38. Clevenger L, Schrepf A, Christensen D, et al. Sleep disturbance, cytokines, and fatigue in women with ovarian cancer. Brain Behav Immun 2012;26:1037-44.

39. de Raaf PJ, Sleijfer S, Lamers $\mathrm{CH}$, et al. Inflammation and fatigue dimensions in advanced cancer patients and cancer survivors: an explorative study. Cancer 2012;118:6005-11.

40. Lasselin J, Layé S, Dexpert S, et al. Fatigue symptoms relate to systemic inflammation in patients with type 2 diabetes. Brain Behav Immun 2012;26:1211-19.

41. Rief W, Mills PJ, Ancoli-Israel S, et al. Overnight changes of immune parameters and catecholamines are associated with mood and stress. Psychosom Med 2010;72:755-62.

42. Geiss A, Rohleder N, Anton F. Evidence for an association between an enhanced reactivity of interleukin-6 levels and reduced glucocorticoid sensitivity in patients with fibromyalgia. Psychoneuroendocrinology 2012;37:671-84.

43. Khan NA, Spencer HJ, Abda E, et al. Determinants of discordance in patients' and physicians' rating of rheumatoid arthritis disease activity. Arthritis Care Res 2012;64:206-14.

44. Sokka T. Morning stiffness and other patient-reported outcomes in rheumatoid arthritis. Scand J Rheumatol 2011;40(Suppl 125):23-7.

45. Bingham CO, Alten R, de Wit MP. The importance of patient participation in measuring rheumatoid arthritis flares. Ann Rheum Dis 2012;71:1107-9.

46. Dougados $\mathrm{M}$, Brault $\mathrm{Y}$, Logeart I, et al. Defining cut-off values for disease activity states and improvement scores for patient-reported outcomes: the example of the Rheumatoid Arthritis Impact of Disease (RAID). Arthritis Res Ther 2012;14:R129

47. Gossec L, Pattemotte S, Aanerud GJ, et al. Finalisation and validation of the rheumatoid arthritis impact of disease score, a patient-derived composite measure of impact of rheumatoid arthritis: a EULAR initiative. Ann Rheum Dis 2011;70:935-42.

48. Boers M. RAID: a valid tool to quantify the impact of rheumatoid arthritis. But what impact will it have on the core set for trials? Ann Rheum Dis 2011;70:884-5.

49. van Steenbergen HW, Tsonaka R, Huizinga TW, et al. Fatigue in rheumatoid arthritis; a persistent problem: a large longitudinal study. RMD Open 2015;1:e000041. 